\title{
CHILDREN'S SOCIAL, EMOTIONAL AND ACADEMIC BEHAVIOR DURING SECOND WAVE OF COVID-19: A PERCEPTION OF SOUTH ASIAN PARENTS
}

\author{
Najmunnisa Khan \\ Associate Professor, Dept. of Education, \\ Shaheed Zulfiqar Ali Bhutto Institute of Science \& Technology, \\ Sindh, Pakistan \\ Email: dr.najmonnisa@szabist.edu.pk

\section{Victoria Joseph} \\ Research Scholar, Dept. of Education, \\ Shaheed Zulfiqar Ali Bhutto Institute of Science \& Technology, \\ Sindh, Pakistan \\ Email: victoria.v.joseph63@gmail.com

\section{Rabia Aslam} \\ Research Scholar, Dept. of Education, \\ Shaheed Zulfiqar Ali Bhutto Institute of Science \& Technology, \\ Sindh, Pakistan \\ Email: rabee_malik@hotmail.com
}

\begin{abstract}
The study explores the perception of parents about their children's social, emotional, and academic behavior during the pandemic, moreover explores the change in parenting style throughout the second wave of COVID-19 pandemic in South Asia. A phenomenological survey was used in the study. 171 parents from South Asia were selected through convenience and purposive sampling technique. An electronic selfdeveloped phenomenological survey questionnaire was distributed through Whatsapp/Email, Moreover 10 parents were also interviewed for triangulation. Descriptive data was analyzed on SPSS-24 and qualitative data was analyzed through thematic analysis. It is found that during the first wave of pandemic COVID-19 lockdown, children were very happy, excited, and active. However, due to long-term school closure, now they are not as much happy but frustrated and they become bored as well. The parents also observed friendly, respectful, and helpful behavior in the children. It is also found that the children love to play, to spend time watching T.V. and on social media, but they didn't show much interest in online study. Parents are also not satisfied with the online classes as the children do not understand content
\end{abstract}


properly. However, this COVID-19 lockdown polished parents' technical skills, and they spend their quality time with children by discussing education and social wellbeing. Findings suggest that children sleeping timing have changed as before lockdown, children used to sleep around 10 p.m. to 11 p.m., but during the lockdown, this routine has changed, and they are sleeping around midnight. The study recommends that adults must be provided with correct information and advice about how their personal well-being and children's well-being can be impacted by this stressful situation.

\section{KEYWORDS}

COVID-19, Social-emotional well-being, Academic behaviour, parenting style

\section{INTRODUCTION}

The coronavirus disease in 2019 (COVID-19) had sudden impact on academic performance and on social, emotional behaviour of people across the world (Patrick et al., 2020). When cases and casualties rose due to this emerging pandemic, governmentwide preventive initiatives of social and physical distance were insured across the nation (Patrick et al., 2020), contributing to sudden closures of educational institutions and workplaces. These trends have resulted in social alienation and psychological instability among adults and children (McGinty et al., 2020), with the highest degree of unemployment, extreme depression and severe economic distress (Hamel et al., 2020).

The lack of economic and psychological support has put a great deal of burden on families with children (Patrick et al., 2020), the risk of economic hardship via acute unemployment and related issues such as food and social security for children also increased. In turn, each of these stressors can increase the family's psychological stress (Lee et al., 2020). Government agencies and clinical associations have expressed concern that children may be at higher risk for social and emotional well-being in particular. The studies report that, children become isolated as they are not in physical or face to face contact with their friends, teachers and even with their relatives. Due to this fact, children are frustrated and started behaving rudely (Auðardóttir \& Rúdólfsdóttir, 2020). Even though the educational institutions are providing regular online educations, the children are not taking interest and could not understand the content unlike the regular education (Amir et al., 2020). Due to long term school closure, children are spending ample time on social media, such as Facebook, Whatsapp, Instagram, twitter etc. (Idoiaga et al., 2020). Despite the concern that many of the squeals associated with the COVID-19 pandemic are at risk for both parents and infants (Karki et al., 2020). Parents are usually loving, kind and take good care of children. But due to pandemic, their parenting style has been changed and at the same time, their teaching technological skills are refined and they spend their quality time 
with children by discussing education and social well-being (Lee et al.,2020). Present study aims to establish how the COVID-19 pandemic and prevention steps have impacted on children`s academic social and emotional well-being in South Asia. Moreover, the study also aims to study the change in parenting style due to school closure during pandemic COVID-19.

\section{LITERATURE REVIEW}

\section{Academic and Socio-emotional needs of children}

Nikolaou (2020) informs that socializing is the process through which children interact with others in any environment. This may include meeting their friends, talking to their teachers, and other social contacts while playing in the playground or any other places. It is pertinent to mention that children had daily interaction with their peers during school days before the pandemic. They played in the parks, met their relatives in any parties, attended weddings of relative, friends and family, and went to the shopping malls and cinema house for more socialization. Children also read, wrote, sang, played, and worked with their peers during school timings, making their lives beautiful and happy. Children were also active in group activities such as playing cricket, swimming, hockey, football and other games where they communicate and interact with everyone. All the above mention activities came to an end when the schools all over the world suddenly closed. The children were left in homes without meeting their friends and teachers, felt bored, nobody to contact and more surprising and sadly quite confused about the country's current situation. So there was total social inactivity. Staying at home during the pandemic was an irreplaceable loss for children. However, children had developed a cordial relationship with their parents and caretakers and spent their quality time in a meaningful manner.

A research was conducted to examine the social, relational, and pedagogical threats and needs of children during the quarantine period in the developmental age (3-18 years) of parents from different Italian regions. The research explored the thoughts of parents on social distance processes and the constant and enormous use of emerging technology for distance learning (DL). The findings revealed that parents have two main health issues, one on health and the other on children's teaching, preparation, and educational routes. In terms of management competence and systemic and infrastructural ability, they displayed distrust and cynicism towards institutions and the school world; aspects viewed as issues for Phase 2 and 3 of the epidemic curve as well (Coppola et al., 2020).

\section{Emotional, Physical, Cognitive impairment}

There was mere uncertainty during pandemic 2019, which affected globally. Closing down of school compelled the children students to stay home, which forced the parents and the care giver to see students' academic needs of students/children (Moroni et al., 
2019). This creates difficulty in the life of children from the underprivileged background. One of the socio-emotional skill of a child is their mental health, wellbeing, and well behaviour were both have a positive and negative effect during a pandemic it entirely depends on the parents and their interaction with their children. Patrick et al., (2020) reported that the COVID-19 pandemic has significantly affected parents and infants, and since the pandemic started, 1 in 7 parents have reported worsening behavioral health for their children.

\section{Parenting Style during the pandemic}

Brown et al. (2020) inform that children benefit and learn skills when there is support and time and interaction from the parent. Parents also have to home school the children due to school closure. During pandemic, it is being noticed that families tend to be spending more time together, exercising, running, and doing school work. Moreover, they are engaged in games, music, watching television together and other creative tasks (Goldschmidt, 2020). Parents have experienced increased pressure to work from home, to keep their work running as well as to take care of schooling children at home at the same time, while caregiver resources including grandparents and the wider family have been restricted (Poudel \& Subedi). With the unprecedented lockdown, most parents have worries about their children's education and future as their school education has been halted until further notice.

\section{Academic during Pandemic through Distance learning}

According to Amir et al. (2020), some countries such as China and Spain have twisted to distance learning to accommodate pandemic situations when schools abruptly closed. Some countries like China uploaded the content materials, resources necessary for education, and made sure the learners' information is available. Spain and other countries suggested and encouraged and asked teachers to create online sessions and offer them. Pandemic has also enhanced the institutional infrastructure facilities such as gadgets and internet connection with great success.

Aleksandra, a mother in Skopje, reportedly informs that television learning has been supportive for parents and children as it helps them adapt to the real situation. She further narrates that "It's a challenge to balance and entertain three kids at home. Auspiciously, the program the T.V. classroom can keep the children occupying sufficiently" (Miks \& Mcllwaine, 2020). Two children from Jakarta have informed that their teachers have been sending the regular assignment for their learning. Another student tells him /her study at home and learning a new language even though he/she missed school but could spend quality time with her/his parents (Christian et al., 2020).

\section{Children lifestyle}

Voitsidis et al. (2020) claim that pandemic had heavily affected children sleeping 
habits. Further on the researcher reveal more than $70 \%$ children under the age of 16 have changed their sleep pattern they sleep late in the night and more than $56 \%$ of the children wake-up late in the morning and around $74 \%$ of the parents confirmed that their children heavily depend on the electronic media.

According to the Goldschmidt (2020) play is an integral part of the physical and social growth of infants. Throughout the COVID-19 pandemic, closures to parks and playgrounds were not uncommon. Each one becomes more confined to the homes. Generally, the monkey bars and swings in parks are buzzing with kids who laugh and play; now, they have yellow caution tape wrapped around them and "playground closed" signs posted. Seeing a regular, innocent playground just seems unfair. Condemned as if it were a threat to defence. This also created negative impact on children`s wellbeing. Both parents and individual stress were included in a report on emotional symptoms, hyperactivity-inattention, and behavior issues (Tobia \& Marzocchi, 2018). The decision of govt. on closing of schools and therefore keeping children locked at home were flawless, however the consequences of all this affected the well-being of families.

A study conducted in China reveal there was no statistically significant difference in childhood symptoms between areas identified by different disease risk levels (Jiao et al., 2020). Likewise, the nature of the atmosphere, such as the physical properties of the living room, is not correlated with the psychological symptoms of parents and children.

According to the Brooks et al,, (2020) parental stress and psychological problems of children are correlated with each other. According to the parents, it is difficult to take care of the learning need of their children, finding room and time for themselves. This underlines that similar structures exist for families with children under 14 years of age with the effect of the lockout on parents and children (Wu et al., 2020). More stressed parents find it harder to consider the needs of their children and to respond sensitively to them (Karki et al., 2020).

Children may feel less understood by their parents in these families and may react in more negative and violent ways as stress is also related to disrespectful attitudes and difficulty in describing discipline and boundaries (Morelli et al., 2020; Pinquart, 2017; Scaramella et al., 2008) In addition, it is understood that children do not have ample personal resources to cope with the many changes placed on their lives by the pandemic (Liu et al., 2020). Parents should speak and explain the situation with their children, as accurate knowledge about what is going on and the reasons for the constraints children have to face is necessary to avoid adverse psychological effects (Griffith, 2020). How and when, however, to do that is left entirely up to the decision 
of the parents. It is assumed that more stressed parents may not find suitable ways to support their children and to find the best ways to answer the questions and fears of children (Hiraoka \& Tomoda, 2020). If children do not find answers from adults or loved ones from home to their questions, they may display more anxiety, demonstrated by more emotional and behavioral responses.

These findings indicate several interesting effects that should be discussed in the present and the future, if we are to encourage the well-being of children and to avoid the onset of more serious behavioral and emotional problems. The pandemic and its quarantine involve the use of personal resources to cope with daily life and feeding. Adults need to be given accurate information and advice about how this stressful situation will impact their personal and children's well-being. For example, public health should provide parents with awareness of how children communicate anxiety at various ages and the value of communicating and talking about worries and negative emotions (Brown et al., 2020).In this way even less resilient and more stressed parents may be helped in finding ways to understand and support their children (Xu et al., 2020).

In addition, we recognize that children do not have enough personal resources to cope with the many changes that the pandemic is bringing on their lives (Liu et al., 2020) and recommendations recommend that parents should address and clarify the situation with them, because accurate knowledge about what is happening and the reasons for the constraints that children have to face is important to avoid adverse psychological effects. How and when to do so, though, is left entirely up to the discretion of the parents.

If children do not find sensitive responses from adults to their complaints, they may display more anxiety, demonstrated by more emotional and behavioral issues, as well as inattention and difficulty concentrating (Brown et al., 2020).

\section{RESEARCH OBJECTIVES}

1. To explore the perceptions of parents regarding their children's life throughout the second wave of COVID-19 pandemic in South Asia.

2. To find out the perceptions of parents regarding their children`s academic and social emotional behavior throughout the second wave of COVID-19 pandemic in South Asia

3. To find out the change in parenting style throughout the second wave of COVID-19 pandemic in South Asia.

\section{RESEARCH QUESTIONS}

1. How do the children feel at home throughout the second wave of COVID-19 
pandemic in South Asia?

2. Is there any change in the children daily routine throughout the second wave of COVID-19 pandemic in South Asia?

3. Is there any change in the children academic and social emotional behaviour throughout the second wave of COVID-19 pandemic in South Asia?

4. What are the significant changes happened to parents in their parenting style throughout the second wave of COVID-19 pandemic in South Asia?

\section{RESEARCH METHODOLOGY}

A phenomenological survey was used in this study (Nayani \& David, 1996). A selfdeveloped survey tool was developed to validate and quantify parents' perception on their children's lives to measure the change in social-emotional behaviour during second wave of COVID-19 pandemic. The study was directed towards exploring the phenomenon of children`s life such as academic, social and emotional wellbeing during pandemic, as well as to study the change in their academic, social and emotional behaviour. The phenomenological research helps us learn from experiences, as it is a powerful research strategy that is well suited for exploring challenging problems experienced by the sample (Neubauer et al.,2019). A phenomenological study is conducted through a survey questionnaire with 171 parents from different socioeconomic diverse communities to discover accurate evidence from the respondent, and researcher also conducted an in-depth interview with 10 parents to triangulate the outcomes of the results, who were directly involved in the phenomenon. Sample of survey and interview were selected through convenience and purposive sampling technique

In order to fulfil the aims of the phenomenological study, semi-structured interview schedule and a survey questionnaire was developed and used for data collection. The survey questionnaire comprised two portions: the first portion dealt with the participating parents' demographic information about their children, such as the school system in which their children studied. Section B had 29 items revolved around how the children spent their time, their emotional behaviour during the locked down period with their parents and change of the parenting style during COVID-19 lockdown. An electronic self-developed phenomenological survey questionnaire was distributed through Whatsapp/Email. Data was analyzed on SPSS-24 through descriptive statistics. Qualitative data was analyzed through thematic analysis.

\section{RESEARCH FINDINGS}

Parents perception regarding their children`s life before and during COVID-19 Lockdown 


\begin{tabular}{|c|c|c|c|c|c|}
\hline \multicolumn{6}{|c|}{$\begin{array}{c}\text { Table } 1 \\
\text { Daily Routing }\end{array}$} \\
\hline Sleeping Routine & $\begin{array}{l}\text { Frequency } \\
\text { (Before } \\
\text { lockdown) }\end{array}$ & $\begin{array}{l}\text { Frequency } \\
\text { (During } \\
\text { lockdown) }\end{array}$ & $\begin{array}{l}\text { Gets Up } \\
\text { Routine }\end{array}$ & $\begin{array}{l}\text { Frequency } \\
\text { (Before } \\
\text { lockdown) }\end{array}$ & $\begin{array}{l}\text { Frequency } \\
\text { (During } \\
\text { lockdown) }\end{array}$ \\
\hline 9 p.m. & 40 & 4 & 9 a.m. & 154 & 50 \\
\hline 10 p.m. & 56 & 18 & 10 a.m. & 2 & 26 \\
\hline 11 p.m. & 50 & 20 & 11 a.m. & 8 & 22 \\
\hline $\begin{array}{l}12 \text { midnight or } \\
\text { after }\end{array}$ & 22 & 126 & 12 noon & 4 & 70 \\
\hline Total & 168 & 168 & Total & 168 & 168 \\
\hline Missing & 3 & 3 & Missing & 3 & 3 \\
\hline System & & & System & & \\
\hline Total & 171 & 171 & Total & 171 & 171 \\
\hline
\end{tabular}

Table 1 shows that out of 171 participants, 3 parents did not respond to the question of children routine, so the response rate was $98.2 \%$. Majority parents expressed that their children sleeping timing have changed as before lockdown, children used to sleep around 10 p.m. to 11 p.m., but during the lockdown, this routine has changed, and $75 \%$ children are sleeping around midnight.

\section{Finding from the Interviews}

The above result shows that, due to spending most of the time on social media as schools were closed and they do not need to get up early for school, as one of the parents infirmed that "we usually go to sleep late as we spend a time on watching T.V dramas while our children spending time with their friends on social media. And we are not worrying about getting up early, as the schools are closed." Parents also observed undisciplined behaviour in their children (Auðardóttir \& Rúdólfsdóttir, 2020). It was also found from the interview that that this COVID-19 pandemic changed the lifestyle of children, they are suffering from insomnia, spent whole night on social media texting with their friends, and as the screen time increases, resulting the sleeping disorder among children (Phelps \& Sperry, 2020). Increased digital times may also result in 'emotional conta-gion' where one spreads to an 'emotional conta-gion' where the anxiety and terror encountered by one extend to another (Kumar et al., 2020).

Parents' perception regarding their children's Academic behaviour during Covid-19 lockdown

Table 2

Attending and feeling about online classes

\begin{tabular}{lccccc}
\hline Attending & Frequency & Percent & Feelings & Frequency & Percent \\
\hline Yes & 108 & 63.2 & $\begin{array}{c}\text { satisfied and can } \\
\text { understand the work }\end{array}$ & 78 & 45.8 \\
\hline \hline
\end{tabular}




\begin{tabular}{lccccc}
\hline No & 62 & 36.3 & $\begin{array}{c}\text { not satisfied and } \\
\text { cannot understand the } \\
\text { work }\end{array}$ & 92 & 54.1 \\
$\begin{array}{l}\text { Total } \\
\text { Missing }\end{array}$ & 170 & 99.4 & $\begin{array}{c}\text { Total } \\
\text { Missing System }\end{array}$ & 170 & 99.4 \\
$\begin{array}{l}\text { System } \\
\text { Total }\end{array}$ & 1 & .6 & Total & 171 & 100.0 \\
\hline $\begin{array}{l}\text { Table 2 illustrates that out of } 171 \text { participants, 1 participant did not respond to this } \\
\text { question, so the response rate was 99.4\%. 63.2\% responded that their children are } \\
\text { taking online classes out of which 54.1\% parents are not satisfied with the online } \\
\text { classes as the children do not understand properly. }\end{array}$
\end{tabular}

\section{Finding from interviews}

Parents were not satisfied regarding the online teachings as their children are not showing any interest and unable to understand any concept. As one of the parent described "my son was not interested in online lessons because he could not understand and do not want to do the homework given by the teacher." One of the mother suggested that online teaching can be fun as she said, "teacher should make the online teaching fun and interesting, so that our children will enjoy learning." Parent also affirms that students are suffering from online classes, they are not taking interest in online classes as the teaching learning process did not meet the expectation and interest of the students (Amir et al., 2020).

Parents perception regarding their children`s emotional behaviour during Covid-19 Lockdown

Table 3

Child's Observable Behaviour during COVID-19 Lockdown

\begin{tabular}{|c|c|c|}
\hline & Frequency & Percent \\
\hline Excited/happy/Active & 72 & 42.1 \\
\hline Friendly/ helpful/ Respectful & 32 & 18.7 \\
\hline Sad/ fear/ nervousness & 12 & 7.0 \\
\hline Angry / Complaining/ irritable & 18 & 10.5 \\
\hline Lazy & 18 & 10.5 \\
\hline Total & 152 & 88.9 \\
\hline Missing System & 19 & 11.1 \\
\hline Total & 171 & 100.0 \\
\hline
\end{tabular}

Table 3 shows the perception of parents regarding the child's feeling during COVID19 lockdown. Data was collected from 171 parents, 19 parents didn't respond to this question so, the response rate was $89 \% .42 \%$ of parents respond that their children are 
very happy and excited, and they become very active during COVID-19 lockdown. 32 parents observe friendly and helpful behaviour in their children. Some of the parents also observe negative feeling in their children as $7 \%$ parents responded that their children are sad at home and missing their friends and school while $11 \%$ parents observed that their children have become lazy, angry, complaining and irritable.

\section{Finding from the Interviews}

Some of the parents from the interview admitted that their children were initially happy but as the month pass, they started missing their school life and demanded activities fun activities from us and when we could not satisfy their needs the children became irritable and upset, and they also started misbehaving (Poudel \& Subedi, 2020). Parents also affirmed that children with coronavirus lockdown experience related negative emotions (Idoiaga et al., 2020; Jiao et al., 2020; Liu et al., 2020). One of the mother observed some negative emotions especially those related to fear, depression, concern, or nervousness in children during this pandemic (Jiloha, 2020), but new emotions have also emerged. In particular, feelings of frustration need to be considered. During the lockdown, children are at high risk factor of negative emotions (Brooks et al., 2020; Wu et al., 2005). It is also found from interview that many children have not had physical access to classmates, peers, schoolmates and family for over two months because of the lockout. Few or no outside play and socialization activities can often negatively affect children, leaving them quickly lonely, upset and irritated. Although many are engaged and virtually linked on mobile phones, it is more likely that they will become deeply interested in social media and online entertainment (Kumar et al., 2020).

Table 4 Children preferences during COVID-19 lockdown

\begin{tabular}{lllll}
\hline & \multicolumn{2}{c}{ Interested } & \multicolumn{2}{c}{ Not Interested } \\
\hline & Frequency & Percent & Frequency & Percent \\
\hline Study & 14 & 8.2 & 76 & 44.4 \\
Play & 66 & 38.6 & 8 & 4.7 \\
Sleep & 6 & 3.5 & 34 & 19.9 \\
Help in home chores & 8 & 4.7 & 30 & 17.5 \\
Watch T.V/ Netflix & 42 & 24.6 & 6 & 3.5 \\
Using social media & 34 & 19.9 & 16 & 9.4 \\
Total & 170 & 99.4 & 170 & 99.4 \\
Missing & 1 & .6 & 1 & .6 \\
System & 171 & 100.0 & 171 & 100.0 \\
Total & \multicolumn{4}{l}{. } \\
Table 4 shows the perception of parents regarding the child's preferences during \\
COVID-19 lockdown. Data was collected from 171 parents, 1 parent didn't respond to \\
\hline
\end{tabular}


this question so, the response rate was $99 \% .8 \%$ of parents respond that their children love to study, while $44 \%$ of parents expressed their children hate to study during COVID-19 lockdown. 39\% parents respond that their children love to play while 5\% parents expressed that their children hate to play during COVID-19 lockdown. 3\% parents respond that their children enjoy sleeping while 20\% parents expressed that their children do not like to sleep unless they tired during COVID-19 lockdown. 5\% parents respond that their children love to help in home chores while $18 \%$ parents respond that their children do not help them in home chores during COVID-19 lockdown. $42 \%$ parents respond that their children love to watch T.V/ Netflix while $4 \%$ parents respond that their children do not like to do this. $20 \%$ parents respond that their children love to spend their time on social media while $9 \%$ parents expressed that their children hate to spend their time on social media during COVID-19 lockdown.

\section{Finding from the Interviews}

Most of the mothers complained that their children were interested in playing all the time rather than studying or doing any homework. Furthermore they said that, "my younger children were interested in playing all the times while my elder son who is studying in grade IX spending all his time on social media chatting with his friends and making Insta story, till late night." Another mother said, "one thing my daughter hated was studying as she would not write anything in their exercise books, I think the teachers must be appreciated as I don't know how they take the work from student and keep them disciplined." One of the mother also confirmed that when the children are out of school for a long time their interest divert from studying to playing (Jiao et al., 2020). It is also found from interview that pandemic made students responsible on doing home chores but as the lockdown period extend, a visible changed were observed in students' attitude. Students started spending more time on social media and academic concerns were left behind (Mangiavacchi et al., 2020).

Change in parenting style during COVID-19 Lockdowns

Table 5

COVID-19 polished parents technological skills

\begin{tabular}{|c|c|c|c|c|c|}
\hline & & Frequency & Percent & $\begin{array}{c}\text { Valid } \\
\text { Percent }\end{array}$ & $\begin{array}{c}\text { Cumulative } \\
\text { Percent }\end{array}$ \\
\hline Yes & & 92 & 53.8 & 79.3 & 79.3 \\
\hline No & & 24 & 14.0 & 20.7 & 100.0 \\
\hline Total & & 116 & 67.8 & 100.0 & \\
\hline Missing & System & 55 & 32.2 & & \\
\hline Total & & 171 & 100.0 & & \\
\hline
\end{tabular}

Table 5 shows either the COVID-19 lockdown polished parents' technological skills or not. 54\% parents agree that in this lockdown they have polished their technological skills while $14 \%$ parents disagree with this statement. 55 parents out of 171 did not 
respond to this question so, and overall response rate was 68\%. It is also confirmed from the mother who were interviewed that their parenting style has been changed from good to worst, initially the parents were good during the beginning month of pandemic but as the time pass, they began to feel the pressure and really felt irritated, upset, and became aggressive as they could not control their children like their teachers.

\section{Finding from the Interviews}

Some of the parents disclosed that they were unable to manage their children academic issues as their children did not want to study and could not understand, however the parents improved their technological skills while assisting their children in online education (Morelli et al., 2020). Xu et al. (2020) also supports that parent benefit and learn a skill when there are support and time.

Table 6

Discussion with children during COVID-19 Lockdown

\begin{tabular}{|c|c|c|c|c|c|}
\hline $\begin{array}{c}\text { Spending } \\
\text { quality time }\end{array}$ & Frequency & Percent & Feelings & Frequency & Percent \\
\hline Yes & 153 & 89.5 & $\begin{array}{c}\text { Emotional } \\
\text { Wellbeing / } \\
\text { Education }\end{array}$ & 123 & 80.4 \\
\hline No & 18 & 10.5 & $\begin{array}{l}\text { Food / cooking / } \\
\text { house chores / } \\
\text { shopping }\end{array}$ & 26 & 17 \\
\hline Total & 171 & 100 & Total & 149 & 97.4 \\
\hline $\begin{array}{l}\text { Missing } \\
\text { System }\end{array}$ & --- & & Missing & 4 & 3 \\
\hline Total & 171 & 100 & Total & 153 & 100 \\
\hline
\end{tabular}

Table 6 illustrates parents' perception about the spending of quality time with children. $10.5 \%$ parents expressed that they do not spend quality time with their children while $153(89.5 \%)$ parents spend quality time with their children during the covid-19 lockdown. Out of 153 parents, $123(80 \%)$ parents spend their quality time with children to discuss education and emotional well-being. In contrast, $26(17 \%)$ parents spend their quality time with their children by discussing food, cooking, house chores, and shopping.

\section{Finding from the Interviews}

Finding from the interview showed that the parents and children spent quality time with each other during the initial month of pandemic, children were interacted well with the family members, and also help in cooking and cleaning, and also took part in the family discussion, as the month pass, both the parents and children began to feel 
anxious, upset, irritated and aggressive (Pinquart, 2017). One of the parent said, "We have the good time in the beginning of the lockdown, but could not continue for a long time due to family, social and academic issues. "Moreover, one of the parent said due to lack of resources such as internet facility, power backup, teaching aids, separate study room, they could not provide quality education to their children (Liu et al., 2020). Parents should speak and explain the situation with their children, as accurate knowledge about what is going on and the reasons for the constraints children have to face is necessary to avoid adverse psychological effects (Griffith, 2020).

\section{CONCLUSION AND DISCUSSIONS}

Covid-19 had brought both positive and negative aspects globally. This research has brought parents' perception on children social and emotional and academic aspects. According to the parents, students spent quality time with them. They spent activities such as cooking, gardening, family discussions and helping the family members, which involved both sibling and the other family members. Students' routines were notably changed, especially going to bed early to bed late as the parents and other family members watched television and went late to bed. Initially both parents and children spent quality time however, both parents and children became upset, irritable and aggressive as both of them could not manage the time and work wisely. On the other hand, children could not follow the online classes and could not show any interest as they could not understand the online teaching method and could not manage the given home tasks. One positive aspect of pandemic is that the parent were able to improve their technological skills while assisting their children in online education.

\section{RECOMMENDATIONS}

From the findings it can be suggested that parents should read storybooks, tell stories and spend quality time to stop their children from watching television. Patriotic stories and reading newspapers and magazine could help children from spending more time on social media. Online classes should be encouraging, interesting, fun-filling and conceptual so that the children will be focused and show interest while attending online classes. Educational institutions should adopt good technological advancement so that they can provide good interesting and purposeful online classes to students. Good videos, experiments and hands on activities, art therapy and fitness yoga would help students enjoy and turn towards online teaching. Teachers' warm welcome to students and interaction with parents will also improve online attendance. Our educational systems should be equipped, embrace technology, professional education to educators and be ready for future catastrophes and calamities. Teachers should create awareness sessions to parents on how to organize manage the task and time meaningfully.

The present study is limited to the perception of South Asian parents. For future, qualitative research with focus group discussions or interview with parents and 
children on social, emotional and academic wellbeing can bring in-depth and meaningful conclusions and results. Researches on technological infrastructure, teaching methods, curriculum of the schools and educational systems can give a bright view on why the students could not understand the concepts during the online sessions

\section{REFERENCES}

Amir, L. R., Tanti, I., Maharani, D. A., Wimardhani, Y. S., Julia, V., Sulijaya, B., \& Puspitawati, R. (2020). Student perspective of classroom and distance learning during COVID-19 pandemic in the undergraduate dental study program Universitas Indonesia. BMC medical education, 20(1), 1-8.

Auðardóttir, A. M., \& Rúdólfsdóttir, A. G. (2020). Chaos ruined the children's sleep, diet and behaviour: Gendered discourses on family life in pandemic times. Gender, Work \& Organization.

Brooks, S. K., Webster, R. K., Smith, L. E., Woodland, L., Wessely, S., Greenberg, N., \& Rubin, G. J. (2020). The psychological impact of quarantine and how to reduce it: rapid review of the evidence. The Lancet.

Brown, S. M., Doom, J. R., Lechuga-Peña, S., Watamura, S. E., \& Koppels, T. (2020). Stress and parenting during the global COVID-19 pandemic. Child abuse \& neglect, 110, 104699.

Christian, M., Purwanto, E., \& Wibowo, S. (2020). Technostress creators on teaching performance of private universities in Jakarta during Covid-19 pandemic. Technology Reports of Kansai University, 62(6), 2799-2809.

Coppola, M., Immacolata, S., \& Masullo, G. (2020). Parents in pandemic: parents' perceptions of risks and psychological, relational, and pedagogical needs in childhood during the COVID-19 emergency in Italy, 103-121.

Fontanesi, L., Marchetti, D., Mazza, C., Di Giandomenico, S., Roma, P., \& Verrocchio, M. C. (2020). The effect of the COVID-19 lockdown on parents: A call to adopt urgent measures. Psychological Trauma: Theory, Research, Practice, and Policy. 79-81.

Foran, H. M., Eckford, R. D., Sinclair, R. R., \& Wright, K. M. (2017). Child mental health symptoms following parental deployment: The impact of parental posttraumatic stress disorder symptoms, marital distress, and general aggression. Sage open, 7(3), 2158244017720484.

Goldschmidt, K. (2020). The COVID-19 pandemic: Technology use to support the wellbeing of children. Journal of Pediatric Nursing.

Griffith, A. K. (2020). Parental burnout and child maltreatment during the COVID-19 pandemic. Journal of family violence, 1-7.

Hamel, L., Kearney, A., Kirzinger, A., Lopes, L., Muñana, C., \& Brodie, M. (2020). KFF Health Tracking Poll-June 2020.

Hiraoka, D., \& Tomoda, A. (2020). The relationship between parenting stress and school closures due to the COVID-19 pandemic. Psychiatry and Clinical Neurosciences. 497-498.

Idoiaga, N., Berasategi, N., Eiguren, A., \& Picaza, M. (2020). Exploring children's social and 
emotional representations of the Covid-19 pandemic. Frontiers in Psychology, 11, 1952.

Jiao, W. Y., Wang, L. N., Liu, J., Fang, S. F., Jiao, F. Y., Pettoello-Mantovani, M., \& Somekh, E. (2020). Behavioral and emotional disorders in children during the COVID-19 epidemic. The journal of Pediatrics, 221, 264.

Jiloha, R. C. (2020). COVID-19 and mental health. Epidemiology International (E-ISSN: 2455 7048), 5(1), 7-9.

Karki, U., Dhonju, G., \& Kunwar, A. R. (2020). Parenting During the COVID-19 Pandemic. JNMA: Journal of the Nepal Medical Association, 58(231), 957.

Kumar, A., Nayar, K. R., \& Bhat, L. D. (2020). Debate: COVID-19 and children in India. Child and adolescent mental health, 25(3), 165-166.

Lee, S. J., Ward, K. P., Chang, O. D., \& Downing, K. M. (2020). Parenting activities and the transition to home-based education during the COVID-19 pandemic. Children and Youth Services Review, 105585.

Liu, X., Kakade, M., Fuller, C. J., Fan, B., Fang, Y., Kong, J., ... \& Wu, P. (2012). Depression after exposure to stressful events: lessons learned from the severe acute respiratory syndrome epidemic. Comprehensive psychiatry, 53(1), 15-23.

Mangiavacchi, L., Piccoli, L., \& Pieroni, L. (2020). Fathers Matter: Intra-Household Responsibilities and Children's Well-being during the COVID-19 Lockdown in Italy, $1-27$.

McGinty, E. E., Presskreischer, R., Han, H., \& Barry, C. L. (2020). Psychological Distress and Loneliness Reported by U.S. Adults in 2018 and April 2020. JAMA.

Miks, J., \& McIlwaine, J. (2020). Keeping the world's children learning through COVID-19. UNICEF.

Morelli, M., Cattelino, E., Baiocco, R., Trumello, C., Babore, A., Candelori, C., \& Chirumbolo, A. (2020). Parents and Children During the COVID-19 Lockdown: The Influence of Parenting Distress and Parenting Self-Efficacy on Children's Emotional WellBeing. Frontiers in Psychology, 11, 2584.

Moroni, G., Nicoletti, C., \& Tominey, E. (2019). Child Socio-Emotional Skills: The Role of Parental Inputs, 1-35.

Nayani, T. H., \& David, A. S. (1996). The auditory hallucination: a phenomenological survey. Psychological medicine, 26(1), 177-189.

Neubauer, B. E., Witkop, C. T., \& Varpio, L. (2019). How phenomenology can help us learn from the experiences of others. Perspectives on medical education, 8(2), 90-97.

Nikolaou, S. M. (2020). The Effects on the Socio-Emotional State of Students in the National Exams in Greece from the Covid-19 Pandemic-Pilot Research. European Journal of Education, 3(2), 1-8.

Patrick, S. W., Henkhaus, L. E., Zickafoose, J. S., Lovell, K., Halvorson, A., Loch, S., ... \& Davis, M. M. (2020). Well-being of parents and children during the COVID-19 pandemic: a national survey. Pediatrics, 146(4), 1-8.

Phelps, C., \& Sperry, L. L. (2020). Children and the COVID-19 pandemic. Psychological Trauma: Theory, Research, Practice, and Policy, 12(S1), S73.

Pinquart, M. (2017). Associations of parenting dimensions and styles with externalizing problems of children and adolescents: An updated meta-analysis. Developmental psychology, 53(5), 873. 
Poudel, K., \& Subedi, P. (2020). Impact of COVID-19 pandemic on socioeconomic and mental health aspects in Nepal. International Journal of Social Psychiatry, 66(8), 748-755.

Scaramella, L. V., Sohr-Preston, S. L., Callahan, K. L., \& Mirabile, S. P. (2008). A test of the Family Stress Model on toddler-aged children's adjustment among Hurricane Katrina impacted and nonimpacted low-income families. Journal of Clinical Child \& Adolescent Psychology, 37(3), 530-541.

Tobia, V., \& Marzocchi, G. M. (2018). The strengths and difficulties questionnaire-parents for Italian school-aged children: psychometric properties and norms. Child Psychiatry \& Human Development, 49(1), 1-8.

Voitsidis, P., Gliatas, I., Bairachtari, V., Papadopoulou, K., Papageorgiou, G., Parlapani, E., ... \& Diakogiannis, I. (2020). Insomnia during the COVID-19 pandemic in a Greek population. Psychiatry Research, 113076.

Wu, M., Xu, W., Yao, Y., Zhang, L., Guo, L., Fan, J., \& Chen, J. (2020). Mental health status of students' parents during COVID-19 pandemic and its influence factors. General Psychiatry, 33(4).

Xu, Y., Wu, Q., Levkoff, S. E., \& Jedwab, M. (2020). Material hardship and parenting stress among grandparent kinship providers during the COVID-19 pandemic: The mediating role of grandparents' mental health. Child Abuse \& Neglect, 110, 104700.

Yeasmin, S., Banik, R., Hossain, S., Hossain, M. N., Mahumud, R., Salma, N., \& Hossain, M. M. (2020). Impact of COVID-19 pandemic on the mental health of children in Bangladesh: A cross-sectional study. Children and youth services review, 117, 105277. 